\title{
OVERVIEW OF MS AND MALDI MS FOR POLYMER ANALYSIS
}

Liang $\mathrm{Li}$

Department of Chemistry, University of Alberta, Edmonton, Alberta, Canada

OLYMER ANALYSIS involves many different activities ranging from average molecular mass determination to detailed characterization of chemical structures or compositions. It is a key step in understanding the relations of chemophysical properties of a polymeric material and its functions. It is essential for quality control of polymeric products as well as in troubleshooting of a polymer manufacturing process. Currently, there is a high demand for developing specialty materials in many applications such as safe water treatment, recyclable materials in high-tech products, and drug delivery systems with improved therapeutic efficacies. Many of the new materials are based on synthetic polymers. One can expect that the field of polymer analysis will continue to become increasingly important in polymer industry and polymer science.

Polymer analysis is often a challenging task, particularly when a polymer is made from new polymer chemistry, catalysis, or formulation process. Fortunately, a great number of analytical techniques are now available for polymer analysis. They include separation techniques [1-7], spectroscopic methods [8-11], NMR [12-14], X-ray [15-17], microscopy [18-21] and other surface characterization tools [22-24], and mass spectrometry (MS) [25-35]. For a given polymeric system, these techniques each having advantages and limitations over the others are often combined to provide a detailed characterization of the system [33-41]. Among them, MS has become an indispensable tool for polymer analysis and has widely been used to study polymer structure, polymer composition, molecular mass and molecular mass distribution, bulk and surface properties, impurity contents, and so on.

MS offers several important attributes for polymer analysis [25-35]. MS, based on accurate mass measurement and/or tandem MS (MS/MS) analysis, can generate rich chemical information that is highly specific for polymer structural analysis. MS is also very sensitive, allowing the detection and identification of minor polymer components or impurities in a composed polymeric material and any by- 
product of polymerization reaction of a desired polymer. Rapid MS analysis can be done for many polymer samples where no prior sample treatment or extensive separation is needed. MS can potentially provide quantitative information required for determination of the average molecular mass and molecular mass distribution of a polymer or characterization of relative amounts of different components of a polymer mixture. Some forms of MS such as secondary ion mass spectrometry (SIMS) can also be used to characterize polymer surfaces [35].

Almost all mass spectrometric techniques developed so far have been tried for polymer analysis, with varying degrees of success; some have been more widely used than the others. Traditional techniques such as electron impact ionization (EI), chemical ionization (CI), and gas chromatography/mass spectrometry (GC/MS) are still used for generating structural or compositional information on polymers, albeit applicable to only low-mass polymers or their precursors (monomers, dimers, etc.). Pyrolysis MS or GC/MS uses a pyrolysis process to thermally degrade polymers, including very high-molecular-mass polymers, to fragment products that are subjected to MS or GC/MS analysis [25]. This technique is still useful for generating chemical information on monomer structures, copolymer repeat units, end groups, and impurities or additives, particularly for those polymers not amendable to modern MS techniques [25]. In applying this technique, one needs to be cautious in interpreting the mass spectral results, as thermal degradation often alters the chemical structures of the polymeric materials. One interesting recent development in pyrolysis MS is to carry out a controlled degradation of polymer so that low-mass polymers or oligomers, instead of very low-mass products suitable for EI or CI, are generated. The low-mass polymers are analyzed using modern techniques such as matrixassisted laser desorption ionization (MALDI) MS [42-44].

In the 1970s and earlier 1980s, active researches were being pursued to develop new ionization sources to overcome the limitations of EI and CI to handle thermally unstable and/or large molecules. Desorption techniques such as SIMS, fast atom bombardment (FAB), and laser desorption/ionization (LDI) were rapidly developed, and many researchers demonstrated that these techniques were useful for not only biopolymer characterization, but also synthetic polymer analysis. In the late 1980s, the introduction of MALDI and electrospray ionization (ESI) opened a new era in mass spectrometric analysis of biomolecules and synthetic polymers. Before MALDI and ESI, MS was limited to the analysis of relatively low-molecular-mass polymers of less than $3000 \mathrm{Da}$. Only in some favorable polymeric systems, such as poly(ethylene glycol) (PEG), MS analysis of up to 10,000 Da could be done [45]. Even for these polymers, the analysis was not routine, and was usually done by an experienced researcher.

ESI can be particularly useful for analyzing high-mass molecules that are easy to form multiply charged gas phase ions. PEG was one of the chemical samples used to illustrate the power of ESI for high-mass analysis in the early development of the ESI technique [46]. PEG can readily form multiply charged ions by attaching multiple sodium or potassium ions to a polymer chain and they are stable in the gas phase. However, a majority of synthetic polymers do not form multiply charged ions easily, and hence ESI has a limited applicability in synthetic polymer analysis, especially for high-mass polymers. Many polymers require the use of metal ions to 
form adduct ions. These adduct ions are not stable in the gas phase and do not survive during the translation from atmosphere to the mass analyzer via an ESI interface. Even if multiply charged ions are formed, to deduce molecular mass or molecular mass distribution information, oligomer ions must be resolved to determine the charge states. This is not trivial as many peaks from oligomers with different numbers of repeat units and different charge states may overlap. In addition, the oligomer distribution from the ESI ions is very sensitive to the experimental conditions such as the skimmer voltages, making accurate determination of the average mass and mass distribution difficult [47-50].

Despite these limitations, ESI can be a very powerful technique for characterizing ESI-able polymers such as low-mass PEGs or some water-soluble polymers with diverse end-group structures [29, 51-53]. This is because ESI offers several important attributes. First of all, ESI can be readily interfaced with solution-based separation techniques such as high-performance liquid chromatography (HPLC) for separating complex mixtures [54-56]. More recently, ion mobility separation in the gas phase can be used to further separate closely related polymeric ions [57-60]. Second, many different types of ESI tandem mass spectrometers, including those capable of carrying out multiple-stage dissociation of an ion, are available for generating structural and compositional information on a polymer sample [61]. Third, multiply charged ions produced by ESI are relatively easier to dissociate than a singly charged ion often found in MALDI [62-66]. Finally, high-performance ESI mass spectrometers such as high-resolution time-of-flight (TOF), Orbitrap, and highfield Fourier transform ion cyclotron resonance (FT-ICR) MS are now available, offering excellent mass resolving power and mass measurement accuracy. Overall, the combination of new separation tools with high-performance ESI MS will likely increase its popularity in polymer analysis, particularly for detailed characterization of chemical structures and compositions of a polymeric system. But, the major obstacle still remains: many polymers simply do not ionize well by ESI.

MALDI MS transforms the practice of polymer characterization. It has now become a widely used technique for analyzing a great variety of polymers. In this book, many aspects of the MALDI MS technique will be discussed in great detail. There are several unique attributes of MALDI MS, together making it a powerful technique for polymer characterization. In MALDI MS, molecular mass and molecular mass distribution information can be obtained for polymers of narrow polydispersity with high precision and speed. The accuracy, although difficult to determine due to the lack of well-characterized standards, appears to be good as well $[67,68]$. The MALDI analysis of polymers does not require the use of polymer standards for mass calibration. Furthermore, this technique uses a minimum amount of solvents and other consumables, which translates into low operational costs. MALDI MS can also provide structural information, if the instrumental resolution is sufficient to resolve oligomers. In this case, monomer and end-group masses can be deduced from the accurate measurement of the mass of individual oligomers. This is particularly true when a high-resolution instrument such as FT-ICR MS is used for polymer analysis. With the use of MALDI MS/MS, structural characterization can be facilitated. Finally, impurities, by-products, and subtle changes in polymer distributions can often be detected even for relatively complex polymeric systems such as copolymers. 
Because of these attributes, in many labs, MALDI MS has become a routine tool for polymer characterization. This is evident from an increasing number of publications in polymer science literature (e.g., Macromolecules), which indicate the use of MALDI MS as a tool for characterizing newly grafted or synthesized polymers. In the industry dealing with polymeric materials, MALDI MS is often combined with other analytical techniques to provide detailed analyses of a polymeric system. In some cases, MALDI MS is the only technique that can provide the information required to solve a practical problem. One example is in the area of product failure analysis involving four copolymer samples [69].

However, current MALDI techniques have several limitations for polymer analysis. Some narrow polydispersity polymers cannot be readily analyzed. There is a need to develop sample preparation protocols to analyze important polymers such as polyethylene, perfluoropolymer, and polycationic polymers. The analysis of polystyrenes with molecular mass up to 1.5 million has been demonstrated. But it remains to be seen how the technique can apply to other high-molecular-mass polymers (MW > 500,000). Searching for sensitive sample preparation methods and improving the overall detection sensitivity of the current MALDI instrument for high-mass analysis are required. The MALDI technique has not yet generated reliable results in direct analysis of broad polydispersity polymers. The instrumental and chemistry problems associated with the analysis of these broad polydispersity polymers have been studied by a number of groups, as discussed in several chapters in this book. We now have a better understanding of the issues involved, and we will see more development in this area in addressing these issues in the near future. Alternatively, gel permeation chromatography or size exclusion chromatography can be combined with MALDI MS for polymers of broad polydispersity. Finally, it is difficult, at present, to deduce quantitative information on polymer mixtures from the MALDI spectra. The overall detection sensitivity for different polymers is not the same. There is no direct correlation between the relative peak areas in the spectra and the relative amounts in the mixture. However, information on relative changes in polymer composition can be obtained, if several polymeric systems containing the same polymer mixture, but different relative amounts, are available for interrogation.

In conclusion, many different mass spectrometric techniques are currently available for detailed characterization of a synthetic polymer. Among them, MALDI MS has been widely used for analyzing a great variety of polymers. It offers some unique attributes while some limitations remain. However, future advances in fundamental studies of the MALDI process, sample preparation methods, ion detection techniques, and data processing issues will undoubtedly enhance its role in polymer science in general. Many of these topics will be the subject of discussion throughout this book.

\section{REFERENCES}

1. Chang, T.Y., Recent advances in liquid chromatography analysis of synthetic polymers, Advanced Polymer Science, 2003, 163, 1-60.

2. Colfen, H.; Antonietti, M., Field-flow fractionation techniques for polymer and colloid analysis, New Developments in Polymer Analytics I, 2000, 150, 67-187. 
3. Berek, D., Coupled liquid chromatographic techniques for the separation of complex polymers, Progress in Polymer Science, 2000, 25(7), 873-908.

4. Pasch, H., Hyphenated techniques in liquid chromatography of polymers, New Developments in Polymer Analytics I, 2000, 150, 1-66.

5. Philipsen, H.J.A., Determination of chemical composition distributions in synthetic polymers, Journal of Chromatography A, 2004, 1037(1-2), 329-350.

6. Messaud, F.A.; Sanderson, R.D.; Runyon, J.R.; Otte, T.; Pasch, H.; Williams, S.K.R., An overview on field-flow fractionation techniques and their applications in the separation and characterization of polymers, Progress in Polymer Science, 2009, 34(4), 351-368.

7. Mori, S.; Barth, H.G. (editors), Size Exclusion Chromatography. Berlin: Springer, 1999.

8. Heigl, N.; Petter, C.H.; Rainer, M.; Najam-Ul-Haq, M.; Vallant, R.M.; Bakry, R.; Bonn, G.K.; Huck, C.W., Near infrared spectroscopy for polymer research, quality control and reaction monitoring, Journal of Near Infrared Spectroscopy, 2007, 15, 269-282.

9. Young, R.J.; Eichhorn, S.J., Deformation mechanisms in polymer fibres and nanocomposites, Polymer, 2007, 48(1), 2-18.

10. Ngamna, O.; Morrin, A.; Killard, A.J.; Moulton, S.E.; Smyth, M.R.; Wallace, G.G., Inkjet printable polyaniline nanoformulations, Langmuir, 2007, 23(16), 8569-8574.

11. Baessler, H. (editor), Optical Techniques to Characterize Polymer Systems. Amsterdam: Elsevier, 1989.

12. Bruch, M.D. (editor), NMR Spectroscopy Techniques, Vol. 21; Practical Spectroscopy Series. 2nd edition. New York: Marcel Dekker, 1996.

13. Brandolini, A.J., Chemical and physical characterization of polymer systems by NMR spectroscopy. In NMR Spectroscopy Techniques, Vol. 21; Practical Spectroscopy Series. 2nd edition (Bruch, M.D., editor). New York: Marcel Dekker, 1996, pp. 525-555.

14. Kitayama, T.; Hatada, K., NMR Spectroscopy of Polymers. New York: Springer Laboratory, 2004.

15. Medhioub, H.; Zerrouki, C.; Fourati, N.; Smaoui, H.; Guermazi, H.; Bonnet, J.J., Towards a structural characterization of an epoxy-based polymer using small-angle X-ray scattering, Journal of Applied Physiology, 2007, 101(4), 6.

16. Elmoutaouakkil, A.; Fuchs, G.; Bergounhon, P.; Peres, R.; Peyrin, F., Three-dimensional quantitative analysis of polymer foams from synchrotron radiation x-ray microtomography, Journal of Physics D: Applied Physics, 2003, A37-A43.

17. Ha, C.S.; Gardella, J.A., X-ray photoelectron spectroscopy studies on the surface segregation in poly(dimethylsiloxane) containing block copolymers, Journal of Macromolecular Science-Polymer Reviews, 2005, C45(1), 1-18.

18. Brostow, W.; Gorman, B.P.; Olea-Mejia, O., Focused ion beam milling and scanning electron microscopy characterization of polymer plus metal hybrids, Materials Letters, 2007, 61(6), 13331336.

19. Wanakule, N.S.; Nedoma, A.J.; Robertson, M.L.; Fang, Z.; Jackson, A.; Garetz, B.A.; Balsara, N.P., Characterization of micron-sized periodic structures in multicomponent polymer blends by ultrasmall-angle neutron scattering and optical microscopy, Macromolecules, 2008, 41(2), 471-477.

20. Opdahl, A.; Koffas, T.S.; Amitay-Sadovsky, E.; Kim, J.; Somorjai, G.A., Characterization of polymer surface structure and surface mechanical behaviour by sum frequency generation surface vibrational spectroscopy and atomic force microscopy, Journal of Physics-Condensed Matter, 2004, 16(21), R659-R677.

21. Gracias, D.H.; Chen, Z.; Shen, Y.R.; Somorjai, G.A., Molecular characterization of polymer and polymer blend surfaces. Combined sum frequency generation surface vibrational spectroscopy and scanning force microscopy studies, Accounts of Chemical Research, 1999, 32(11), 930-940.

22. Chan, C.M.; Weng, L.T., Applications of X-ray photoelectron spectroscopy and static secondary ion mass spectrometry in surface characterization of copolymers and polymers blends, Reviews in Chemical Engineering, 2000, 16(4), 341-408.

23. Sarac, A.S.; Geyik, H.; Parlak, E.A.; Serantoni, M., Electrochemical composite formation of thiophene and N-methylpyrrole polymers on carbon fiber microelectrodes: morphology, characterization by surface spectroscopy, and electrochemical impedance spectroscopy, Progress in Organic Coatings, 2007, 59(1), 28-36. 
24. Werner, C.; Jacobasch, H.J., Surface characterization of polymers for medical devices, International Journal of Artificial Organs, 1999, 22(3), 160-176.

25. Sobeih, K.L.; Baron, M.; Gonzalez-Rodriguez, J., Recent trends and developments in pyrolysis-gas chromatography, Journal of Chromatography A, 2008, 1186(1-2), 51-66.

26. Montaudo, G.; Samperi, F.; Montaudo, M.S., Characterization of synthetic polymers by MALDI-MS, Progress in Polymer Science, 2006, 31(3), 277-357.

27. Klee, J.E., Mass spectrometry of step-growth polymers, European Journal of Mass Spectrometry, 2005, 11(6), 591-610.

28. Murgasova, R.; Hercules, D.M., Polymer characterization by combining liquid chromatography with MALDI and ESI mass spectrometry, Analytical and Bioanalytical Chemistry, 2002, 373(6), 481-489.

29. Hanton, S.D., Mass spectrometry of polymers and polymer surfaces, Chemical Reviews, 2001, 101(2), 527-569.

30. Adriaens, A.; Van Vaeck, L.; Adams, F., Static secondary ion mass spectrometry (S-SIMS) Part 2: material science applications, Mass Spectrometry Reviews, 1999, 18(1), 48-81.

31. Nielen, M.W.F., MALDI time-of-flight mass spectrometry of synthetic polymers, Mass Spectrometry Reviews, 1999, 18(5), 309-344.

32. Wang, F.C.Y., Polymer analysis by pyrolysis gas chromatography, Journal of Chromatography A, 1999, 843(1-2), 413-423.

33. Pasch, H.; Schrepp, W., MALDI-TOF Mass Spectrometry of Synthetic Polymers. New York: Springer, 2003.

34. Montaudo, G.; Lattimer, R.P. (editors), Mass Spectrometry of Polymers. New York: CRC, 2001.

35. Briggs, D., Surface Analysis of Polymers by XPS and Static SIMS. New York: Cambridge University Press, 2005.

36. Brady, R.F. (editor), Comprehensive Desk Reference of Polymer Characterization and Analysis. Washington DC: American Chemical Society, 2003.

37. Pethrick, R.A.; Dawkins, J.V. (editors), Modern Techniques for Polymer Characterization. New York: Wiley, 1999.

38. Simon, G.P. (editor), Polymer Characterization Techniques and Their Application to Blends. Washington DC: American Chemical Society, 2003.

39. Crompton, T.R., Polymer Reference Book. New York: Rapra Technology, 2006.

40. Schroeder, E.; Mueller, G.; Arndt, K.F., Polymer Characterization. Cincinnati: Hanser, 1990.

41. Kroschwitz, J.I. (editor), Polymers: Polymer Characterization and Analysis. New York: Wiley, 1990.

42. Barton, Z.; Kemp, T.J.; Buzy, A.; Jennings, K.R., Mass spectral characterization of the thermal degradation of poly(propylene oxide) by electrospray and matrix-assisted laser desorption ionization, Polymer, 1995, 36(26), 4927-4933.

43. Puglisi, C.; Samperi, F.; Carroccio, S.; Montaudo, G., MALDI-TOF investigation of polymer degradation: pyrolysis of poly(bisphenol A carbonate), Macromolecules, 1999, 32(26), 88218828.

44. Montaudo, G.; Carroccio, S.; Puglisi, C., Thermal and thermoxidative degradation processes in poly(bisphenol A carbonate), Journal of Analytical and Applied Pyrolysis, 2002, 64(2), 229-247.

45. Lubman, D.M. (editor), Lasers and Mass Spectrometry. New York: Oxford University Press, 1990.

46. Fenn, J.B.; Mann, M.; Meng, C.K.; Wong, S.F.; Whitehouse, C.M., Electrospray ionization for massspectrometry of large biomolecules, Science, 1989, 246(4926), 64-71.

47. Latourte, L.; Blais, J.C.; Tabet, J.C.; Cole, R.B., Desorption behavior and distributions of fluorinated polymers in MALDI and electrospray ionization mass spectrometry. Analytical Chemistry, 1997, 69(14), 2742-2750.

48. Parees, D.M.; Hanton, S.D.; Clark, P.A.C.; Willcox, D.A., Comparison of mass spectrometric techniques for generating molecular weight information on a class of ethoxylated oligomers. Journal of the American Society for Mass Spectrometry, 1998, 9(4), 282-291.

49. Yan, W.Y.; Ammon, D.M.; Gardella, J.A.; Maziarz, E.P.; Hawkridge, A.M.; Grobe, G.L.; Wood, T.D., Quantitative mass spectrometry of technical polymers: a comparison of several ionization methods, European Mass Spectrometry, 1998, 4(6), 467-474.

50. Maziarz, E.P.; Baker, G.A.; Lorenz, S.A.; Wood, T.D., External ion accumulation of low molecular weight poly(ethylene glycol) by electrospray ionization Fourier transform mass spectrometry, Journal of the American Society for Mass Spectrometry, 1999, 10(12), 1298-1304. 
51. Guittard, J.; Tessier, M.; Blais, J.C.; Bolbach, G.; Rozes, L.; Marechal, E.; Tabet, J.C., Electrospray and matrix-assisted laser desorption/ionization mass spectrometry for the characterization of polyesters, Journal of Mass Spectrometry, 1996, 31(12), 1409-1421.

52. Hart-Smith, G.; Lammens, M.; Du Prez, F.E.; Guilhaus, M.; Barner-Kowollik, C., ATRP poly(acrylate) star formation: a comparative study between MALDI and ESI mass spectrometry, Polymer, 2009, 50(9), 1986-2000.

53. Benomar, S.H.; Clench, M.R.; Allen, D.W., The analysis of alkylphenol ethoxysulphonate surfactants by high-performance liquid chromatography, liquid chromatography-electro spray ionisation-mass spectrometry and matrix-assisted laser desorption ionisation-mass spectrometry, Analytica Chimica Acta, 2001, 445(2), 255-267.

54. Feldermann, A.; Toy, A.A.; Davis, T.P.; Stenzel, M.H.; Bamer-Kowollik, C., An in-depth analytical approach to the mechanism of the RAFT process in acrylate free radical polymerizations via coupled size exclusion chromatography-electrospray ionization mass spectrometry (SEC-ESI-MS), Polymer, 2005, 45(19), 8448-8457.

55. Hart-Smith, G.; Chaffey-Millar, H.; Barner-Kowollik, C., Living star polymer formation: detailed assessment of poly(acrylate) radical reaction pathways via ESI-MS, Macromolecules, 2008, 41(9), 3023-3041.

56. Gruendling, T.; Guilhaus, M.; Barner-Kowollik, C., Quantitative LC-MS of polymers: determining accurate molecular weight distributions by combined size exclusion chromatography and electrospray mass spectrometry with maximum entropy data processing, Analytical Chemistry, 2008, 80(18), 6915-6927.

57. Robinson, E.W.; Garcia, D.E.; Leib, R.D.; Williams, E.R., Enhanced mixture analysis of poly(ethylene glycol) using high-field asymmetric waveform ion mobility spectrometry combined with Fourier transform ion cyclotron resonance mass spectrometry, Analytical Chemistry, 2006, 78(7), 21902198.

58. Bagal, D.; Zhang, H.; Schnier, P.D., Gas-phase proton-transfer chemistry coupled with TOF mass spectrometry and ion mobility-MS for the facile analysis of poly(ethylene glycols) and PEGylated polypeptide conjugates, Analytical Chemistry, 2008, 80(7), 2408-2418.

59. Kanu, A.B.; Dwivedi, P.; Tam, M.; Matz, L.; Hill, H.H., Ion mobility-mass spectrometry, Journal of Mass Spectrometry, 2008, 43(1), 1-22.

60. Trimpin, S.; Plasencia, M.; Isailovic, D.; Clemmer, D.E., Resolving oligomers from fully grown polymers with IMS-MS, Analytical Chemistry, 2007, 79(21), 7965-7974.

61. Koster, S.; Duursma, M.C.; Boon, J.J.; Nielen, M.W.F.; de Koster, C.G.; Heeren, R.M.A., Structural analysis of synthetic homo- and copolyesters by electrospray ionization on a Fourier transform ion cyclotron resonance mass spectrometer, Journal of Mass Spectrometry, 2000, 35(6), 739748 .

62. Chen, R.; Li, L., Lithium and transition metal ions enable low energy collision-induced dissociation of polyglycols in electrospray ionization mass spectrometry, Journal of the American Society for Mass Spectrometry, 2001, 12(7), 832-839.

63. Giordanengo, R.; Viel, S.; Allard-Breton, B.; Thevand, A.; Charles, L., Tandem mass spectrometry of poly(methacrylic acid) oligomers produced by negative mode electrospray ionization, Journal of the American Society for Mass Spectrometry, 2009, 20(1), 25-33.

64. Jackson, A.T.; Slade, S.E.; Thalassinos, K.; Scrivens, J.H., End-group characterisation of poly(propylene glycol)s by means of electrospray ionisation-tandem mass spectrometry (ESI-MS/ MS), Analytical and Bioanalytical Chemistry, 2008, 392(4), 643-650.

65. Chen, R.; Yu, X.L.; Li, L., Characterization of poly(ethylene glycol) esters using low-energy collision-induced dissociation in electrospray ionization mass spectrometry, Journal of the American Society for Mass Spectrometry, 2002, 13(7), 888-897.

66. Stenson, A.C.; Landing, W.M.; Marshall, A.G.; Cooper, W.T., Ionization and fragmentation of humic substances in electrospray ionization Fourier transform-ion cyclotron resonance mass spectrometry, Analytical Chemistry, 2002, 74(17), 4397-4409.

67. Guttman, C.M.; Wetzel, S.J.; Blair, W.R.; Fanconi, B.M.; Girard, J.E.; Goldschmidt, R.J.; Wallace, W.E.; VanderHart, D.L., NIST-sponsored interlaboratory comparison of polystyrene molecular mass distribution obtained by matrix-assisted laser desorption/ionization time-of-flight mass spectrometry: statistical analysis, Analytical Chemistry, 2001, 73(6), 1252-1262. 
68. Guttman, C.M.; Wetzel, S.J.; Flynn, K.M.; Fanconi, B.M.; VanderHart, D.L.; Wallace, W.E., Matrixassisted laser desorption/ionization time-of-flight mass spectrometry interlaboratory comparison of mixtures of polystyrene with different end groups: statistical analysis of mass fractions and mass moments, Analytical Chemistry, 2005, 77(14), 4539-4548.

69. Chen, R.; Tseng, A.M.; Uhing, M.; Li, L., Application of an integrated matrix-assisted laser desorption/ionization time-of-flight, electrospray ionization mass spectrometry and tandem mass spectrometry approach to characterizing complex polyol mixtures, Journal of the American Society for Mass Spectrometry, 2001, 12(1), 55-60. 